Bull. Mater. Sci., Vol. 6, No. 2, May 1984, pp. 327-338. (C) Printed in India.

\title{
Amorphous state ferroelectricity, magnon scattering and phase stability in microparticle materials
}

\author{
M S MULTANI, P AYYUB, V R PALKAR, M R SRINIVASAN, \\ V SARASWATI, R VIJAYARAGHAVAN and D O SHAH*
}

Materials Research Group, Tata Institute of Fundamental Research, Bombay 400005 , India. - Department of Chemistry, University of Florida, Gainesville, Florida 32611, USA.

\begin{abstract}
Microparticles and micrograin ceramics show features distinct from the usualsized polycrystalline materials. Amorphous state material combined with microparticle size for $\mathrm{Pb}\left(\mathrm{Zr}_{0.51} \mathrm{Ti}_{0.49}\right) \mathrm{O}_{3}$ mimics the dielectric behaviour of crystalline ferroelectricity in $\mathrm{ABO}_{3}$ compounds. Fine-grained $\mathrm{Y}_{3} \mathrm{Fe}_{5} \mathrm{O}_{12}$ (YIG) synthesized by pressure sintering of YIG microparticles exhibit spinwave relaxation due to transit time across grain diameter. Applying microemulsion techniques for microparticle synthesis, $\gamma-\mathrm{Fe}_{2} \mathrm{O}_{3}$ has been synthesized. The phase stability fraction $\gamma-\mathrm{Fe}_{2} \mathrm{O}_{3} / \alpha-\mathrm{Fe}_{2} \mathrm{O}_{3}$ is found to be a function of particle size. At very small sizes $\gamma-\mathrm{Fe}_{2} \mathrm{O}_{3}$ becomes amorphous, leading to interesting Mössbauer studies.
\end{abstract}

Keywords. Microparticle; microemulsion; ferroelectricity; ferrimagnetism; magnon scattering: lead zirconate titanate; yttrium iron garnet; gamma- $\mathrm{Fe}_{2} \mathrm{O}_{3}$; Mössbauer spectroscopy.

\section{Amorphous and microparticle $\mathrm{Pb}\left(\mathrm{Zr}_{0.51} \mathrm{Ti}_{0.49}\right) \mathrm{O}_{3}$}

The dielectric behaviour of amorphous microparticle $\mathrm{Pb}\left(\mathrm{Zr}_{0.51} \mathrm{Ti}_{0.49}\right) \mathrm{O}_{3}$ has been studied. The dielectric properties indicate the presence of a polar glassy phase transition at $230^{\circ} \mathrm{C}$ and has been interpreted in terms of the ferroelectric glass model described by Lines $(1977,1978)$.

\subsection{Introduction}

Amorphous solids are derived from prototype crystalline structures which have dominantly metallic, covalent or ionic character for chemical bonding. The first two types have been studied extensively but the ionically-bonded ones have not received much attention. The main difference which arises on going from the crystalline to the amorphous state is the tendency of the coordination to decrease for the covalentlybonded materials, to increase for the metallic-bonded ones, and to remain unchanged for the ionic-bonded.

From Mössbauer and EPR data it has been established that the bonding in the $\mathrm{ABO}_{3}$ ferroelectrics is mainly of ionic character (Bhide and Multani 1965 and references therein). Also, Lines $(1977,1978)$ has proposed a model for an $\mathrm{ABO}_{3}$ ferroelectric glass and analysed the possibility of dielectric anomalies in such a system. Subsequently, $\mathrm{LiNbO}_{3}$ and $\mathrm{LiTaO}_{3}$ (Glass et al 1977a), $\mathrm{Pb}_{5} \mathrm{Ge}_{3} \mathrm{O}_{11}$ (Glass et al 1977b), $\mathrm{PbTiO}_{3}$ (Takashige and Nakamura 1980) have been prepared in the amorphous state and their dielectric behaviour has been well-studied.

From the practical point of view polycrystalline $\mathrm{Pb}\left(\mathrm{Zr}_{0.51} \mathrm{Ti}_{0.49}\right) \mathrm{O}_{3}$ (PZr) has found a very large application because of the high $d_{33}$ piezoelectric constant and high $k_{p}$, the planar electromechanical coupling factor. 


\subsection{Experimental}

PZT in the amorphous state was prepared by the sol-gel technique. $\mathrm{Pb}\left(\mathrm{NO}_{3}\right)_{2}, \mathrm{ZrOCl}_{2}$ and $\mathrm{TiCl}_{4}$ were used for synthesis. The solutions of the above salts were mixed in the proportion required to achieve correct stoichiometry. The solutions were mixed in the presence of $\mathrm{NH}_{4} \mathrm{NO}_{3}$ to avoid the formation of insoluble $\mathrm{PbCl}_{2}$. When the homogeneous solution was added to $\mathrm{NH}_{4} \mathrm{OH}$ and stirred, lead, zirconium and titanium got co-precipitated as hydroxides. The complex formed in this step was allowed to settle and the supernatant decanted out. The precipitate was repeatedly washed in order to remove salts like $\mathrm{NH}_{4} \mathrm{Cl}$ and $\mathrm{NH}_{4} \mathrm{NO}_{3}$ as well as the excess alkali. The stable sol of the complex was then prepared and dried. It was then subjected to DTA and TGA studies which indicated that the complex hydroxide decomposed into PZT. That this was singlestep process is evident from the following arguments. The TGA showed a weight loss about $20 \%$ which is in good agreement with the value of $15 \%$ expected for the breaking of the complex $\mathrm{Pb}\left(\mathrm{Zr}_{0.51} \mathrm{Ti}_{0.49}\right) \mathrm{O}_{3}$. $(\mathrm{OH})_{6}$ into PZT. Furthermore, the DTA of the complex showed a single sharp peak at $280^{\circ} \mathrm{C}$ indicating that the decomposition of the

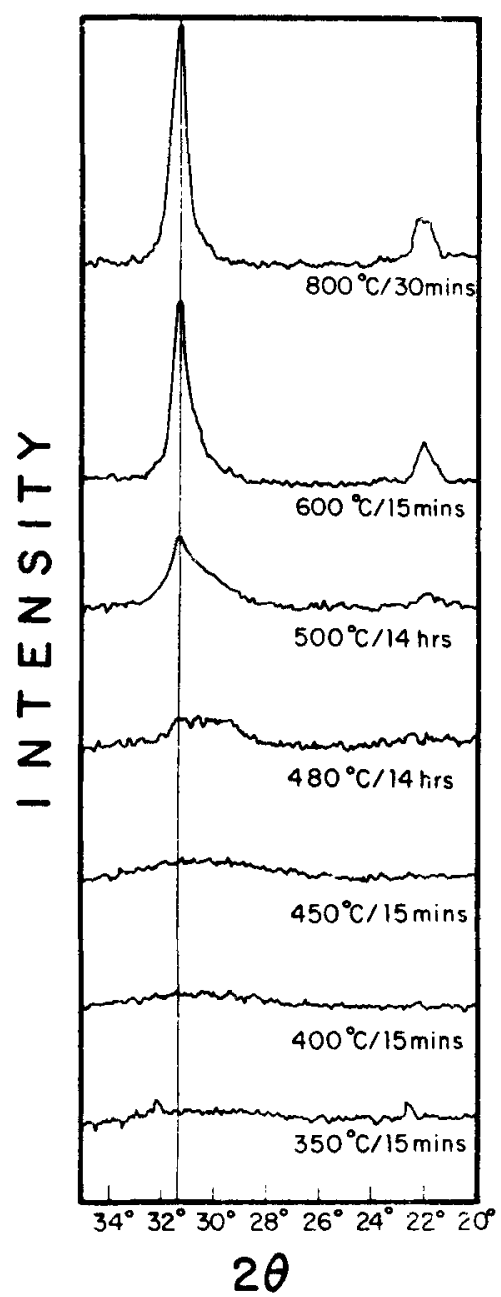

Figure 1. X-ray diffractogram indicating the amorphous-to-crystalline transition in PZT. 
complex occurred in a single step. In contrast, the DTA for the conventional method of preparation indicates three peaks corresponding to the following reactions.

$$
\begin{aligned}
& \mathrm{PbO}+\mathrm{TiO}_{2} \rightarrow \mathrm{PbTiO}_{3} \text { at } 610-710^{\circ} \mathrm{C}, \\
& \mathrm{PbTiO}_{3}+\mathrm{PbO}+\mathrm{ZrO}_{2} \rightarrow \mathrm{PbO} \text { (solid solution) at } 710-790^{\circ} \mathrm{C}, \\
& \mathrm{PbO} \text { (solid solution) }+\mathrm{PbTiO}_{3} \rightarrow \mathrm{Pb}\left(\mathrm{Zr}_{x} \mathrm{Ti}_{3}\right) \mathrm{O}_{3} .
\end{aligned}
$$

$X$-ray diffraction clearly showed that the PZT so formed was in the amorphous state. The equivalent spherical diameter of the particles was calculated to be $40 \mathrm{~nm}$ from surface area analysis using the Brunauer-Emmett-Teller technique. Thus the particle size was not small enough to produce appreciable broadening of the XRD lines. The crystalline PZT could be obtained by suitable heat treatment at higher temperature as shown in figure 1.

\subsection{Results and discussion}

The dielectric constant of the amorphous PZT was measured on pressed pellets of about $1 \mathrm{~cm}$ diameter and $0.1 \mathrm{~cm}$ thickness. The capacitance was measured using a Wayne Kerr autobalance universal bridge. Figure 2 shows the temperature dependence of the dielectric constant. The dielectric constant shows a broad peak at $230^{\circ} \mathrm{C}$ and a sharp peak at $460^{\circ} \mathrm{C}$. The latter peak was identified to be due to the crystallization on the basis of the DTA results which showed a broad exothermic peak at this temperature. DTA data also indicated that the transition at $230^{\circ} \mathrm{C}$ was of the second order. It was found that the lower dielectric peak persisted even on repeatedly cycling the material below the crystallization point, indicating that the peak did not arise from local relaxations. In the subsequent heating cycles up to $500^{\circ} \mathrm{C}$ both the dielectric peaks at 230 and $460^{\circ} \mathrm{C}$ disappeared. Instead there was a single peak at $325^{\circ} \mathrm{C}$ corresponding to the ferroelectric paraelectric transition in crystalline Pzr.

The concept of a ferroelectric glass was initially investigated by Lines under the assumption that the system was far below the crystallization temperature (Lines 1977). This theory was later modified to include the effects of the intrinsic glass softening (Lines 1978). The glassy phase is supposed to contain frozen-in dipoles with random magnitudes and orientations. These are formed by the distortion of dielectrically soft prototype units (e.g. $\mathrm{BO}_{6}$ octahedra in the $\mathrm{ABO}_{3}$ type compounds) which presumably retain their identity even in the glassy phase. As the crystallization temperature $\left(T_{\mathrm{cr}}\right)$ is approached from below, the tendency of these dipoles to become de-frozen leads to a large dielectric anomaly at or near $T_{\mathrm{cr}}$. It is important to note that the above described anomaly would be found in any material with such dielectrically soft units, irrespective of whether it is a ferroelectric. In figure 2 the peak at $460^{\circ} \mathrm{C}$ can be identified with such an anomaly. The anomaly at $230^{\circ} \mathrm{C}$ may be considered to be analogous to a regular paraelectric-ferroelectric phase transition that occurs in crystals due to the cancellation of short range stabilizing forces and long range dipolar forces.

Lines (1978) assumed a simple 2-parameter form for the local mode frequency $\omega(T)$ and the temperature dependence of the dielectric response function is obtained in the mean field approximation

$$
\begin{aligned}
& \varepsilon=4 \pi \alpha \theta /(1-V \alpha \theta): \text { non-polar phase, } \\
& \varepsilon=4 \pi(1 \cdot 5-V \alpha \theta) / V\left(V^{\prime} \alpha \theta-1\right): \text { polar phase, }
\end{aligned}
$$




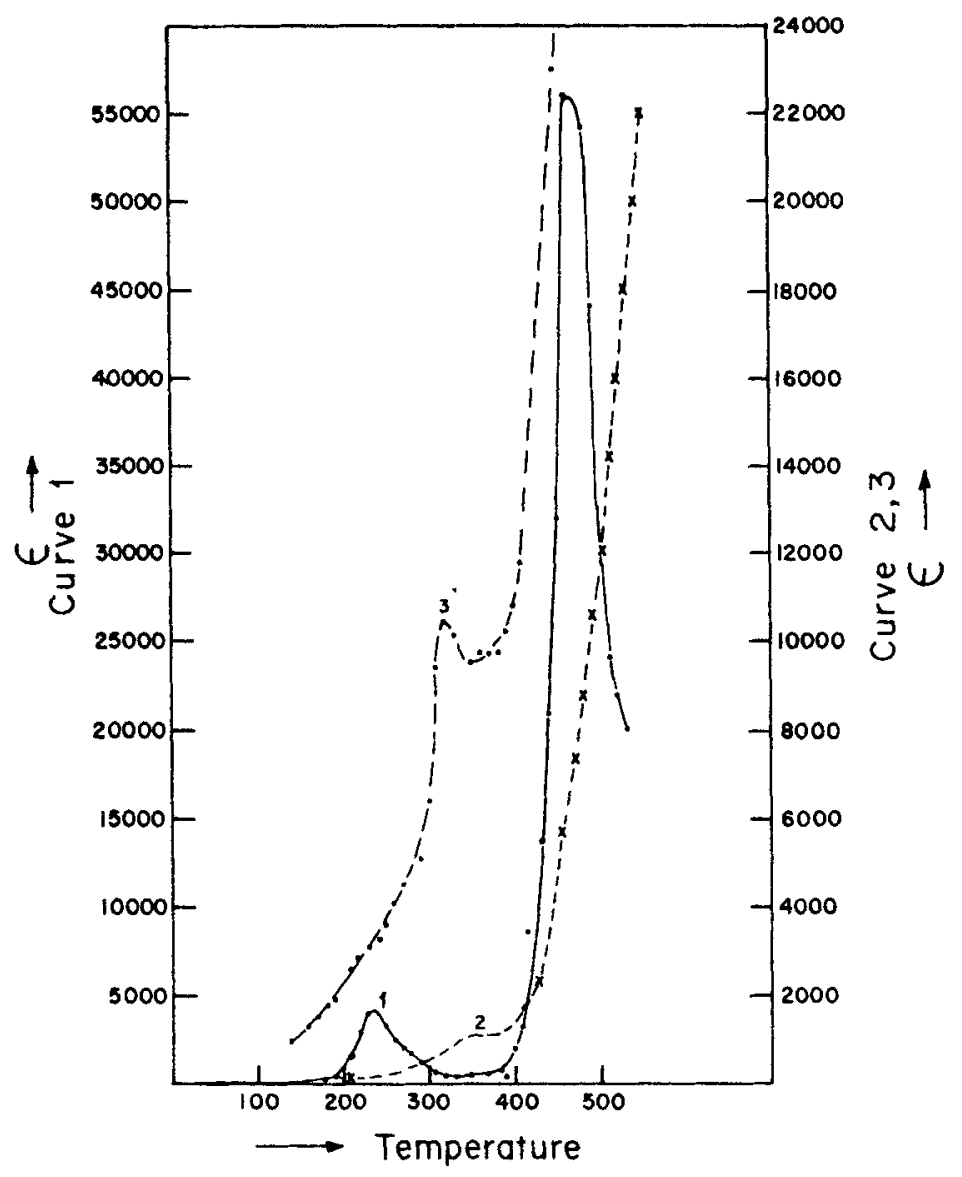

Figure 2. Temperature dependence of the dielectric constant in amorphous PZT.

where $V=4 \pi / 3$,

$\alpha=$ soft unit polarizability,

$\theta=1+a \cdot \exp [-p(1-t)]-b t$ with $t=T / T_{\mathrm{cr}}$,

$a=S^{2} \Delta / \alpha \omega^{2}$, is a measure of the mode softening

$b=12 A S^{2} k T_{\mathrm{cr}} / \alpha \omega^{6}$, is a measure of anharmonicity.

The dielectric behaviour can be qualitatively studied by investigating the temperature dependence of the function $(\theta-3 / 4 \pi \alpha)$ where the second term is constant. Since $\left(d^{2} \theta / d t^{2}\right)$ is necessarily positive it is impossible to obtain the dielectric behaviour observed by us. At best one can obtain two singularities; one at $T_{\mathrm{cr}}$ and another at a temperature below but close to it, but not a finite maximum at a temperature considerably below $T_{\mathrm{cr}}$. In any case the above theory should not be expected to hold quantitatively over a wide temperature range. 
However, precisely because the two peaks are comparatively well-separated it is possible to adopt the following approach. We can fit the higher dielectric peak with (1) and (2) which describe the nature of anomalies close to $T_{\mathrm{cr}}$. Since in the present case the anomaly occurs at $T=T_{\mathrm{cr}}$, we can express in terms of $a$ and $b$ :

$$
3 / 4 \pi \alpha=\theta_{\mathrm{cr}}=1+a-b .
$$

Thus it is possible to determine the temperature-independent material constants $a$ and $b$ and the parameter $p$ from the data. The lower dielectric peak may then be studied using the approach of Lines where the local mode frequency and the mean square static displacement of the ions from the prototype symmetry are assumed to be temperature independent (provided $T \ll T_{\mathrm{cr}}$ ). Under this approximation a ferroelectric phase transition is predicted to occur at:

$$
T_{c}^{\text {glass }}=T_{\mathrm{cr}}(\alpha-3 / 4 \pi) / \alpha b
$$

It is possible to fit (1) with reasonable accuracy to the higher dielectric peak taking $a=0.0100, b=0.0272$ and $p=2.5$. We then consider a dielectric glass for which the constants $a$ and $b$ (and hence $\alpha$ ) are known and try to find the temperature (if any) at which it may undergo a ferroelectric-paraelectric transition. Thus from (3) we find that

$$
T_{c}^{\text {glass }}=190^{\circ} \mathrm{C}
$$

which is reasonably close to the low temperature dielectric peak that was found in the sample at $T=230^{\circ} \mathrm{C}$. This finding also seems to be in accordance with two other predictions of Lines (1977), viz. that, in general

$$
T_{c}^{\text {glass }}<T_{c}^{\text {cryst }}\left(325^{\circ} \mathrm{C}\right)
$$

and that for a material with symmetric prototype units $T_{c}^{\text {glass }}$ should not be too far below $T_{c}^{\text {cryst. }}$.

It is important to stress here that the PZT studied is not only amorphous but microparticle as well. The studies of Känzig et al (1954) Känzig (1955), our recent work (Srinivasan et al 1983 and references therein) have repeatedly shown that the spontaneous strain and the dielectric anomaly decrease substantially, while $T_{c}$ increases when the crystalline $\mathrm{ABO}_{3}$ ferroelectric is reduced in size from $1000 \mathrm{~nm}$ to $10 \mathrm{~nm}$.

\section{Magnon scattering in fine-grained yIG}

\subsection{Introduction}

Yttrium iron garnet (YIG) is a microwave ferrite and owing to the existence of grains and grain boundaries has specific characteristics. Fine-grained ferrites (of average diameter $5 \mu \mathrm{m}$ or less) have become technologically significant in making devices due to their efficiency in handling microwave power (Hudson 1970). The microstructure is largely determined and controlled by preparation procedures. We have succeeded in obtaining highly dense (above $99 \%$ theoretical density) YIG of submicron and micron size using sol-gel method for the preparation of yig powder and sintering of the compacts at high pressures $\left(\sim 2000 \mathrm{~kg} / \mathrm{cm}^{2}\right)$. The grain size dependence of the microwave properties were studied, Our observations on ferrimagnetic resonance linewidths, magnetization, susceptibility and spin wave instability threshold fields are reported herein. 


\subsection{Experimental results}

The YIG powder was made by the sol-gel technique (Multani et al 1981) using yttrium and iron oxides of five-nine purity to avoid fast relaxing rare earth impurities. A few cold-pressed compacts were sintered in oxygen atmosphere for $2 \mathrm{hr}$ at $1400^{\circ} \mathrm{C}$. These compacts had grains of average size $2.5 \mu \mathrm{m}$, assuming the distribution to be log-normal. The densities as measured by loss of weight in water were better than $5 \cdot 14$ (theoretical density of YIG is 5.17). Fine-grain samples were obtained by hot pressing the compacts in a silicon carbide die at $1100^{\circ} \mathrm{C}$ (inside die) at a pressure of $1800-2000 \mathrm{~kg} / \mathrm{cm}^{2}$ for soaking times of 10, 20, 30 and $60 \mathrm{~min}$. These have been numbered as $\mathrm{HP}_{5}, \mathrm{HP}_{4}, \mathrm{HP}_{3}$ and $\mathrm{HP}_{2}$ respectively. The grain size as (average) measured from scanning electron microphotographs were $1 \cdot 1,0 \cdot 9,1 \cdot 2$ and $1 \cdot 34 \mu \mathrm{m}$, respectively. The densities were found to be good - higher than 5.14 and close to $5 \cdot 16 \mathrm{g.} \mathrm{cm}^{-3}$ in one of them. The saturation magnetization values, which also reflect on the densities, were estimated using a B-H loop tracer. These were close to the single crystal values. In polished, spherical samples of size $\sim 0.5$ to $1 \mathrm{~mm}$, ferrimagnetic resonance measurements were carried out at a frequency of $9.25 \mathrm{GHz}$. The uniform precession linewidths $\Delta H$ and magnetization data are given in table 1 . The log-log plot of linewidth $v$ s grain size gives a power law dependence $a^{-0.6}$ where $a$ is the average grain diameter (figure 3). DC magnetic susceptibility and $T_{N}$ measurements were conducted using Bruker instrument at low fields 100 and $250 \mathrm{Oe}$ in annealed spherical samples and irregular annealed pieces. As expected, susceptibility values reduced on annealing and increased with decreasing field.

As YIG is an ordered ferrimagnet at room temperature even at low fields of 100 and $250 \mathrm{Oe}$, the sample gets attracted to the pole piece and there is difficulty in adjusting the balance weight in the susceptibility instrument. In small, spherical samples, sticking

Table 1. Characterization data on vIG

\begin{tabular}{|c|c|c|c|c|c|}
\hline Samples & $\begin{array}{l}\text { Grain } \\
\text { size } \\
(\mu \mathrm{m})\end{array}$ & $\begin{array}{c}\text { Density } \\
(\mathrm{g} / \boldsymbol{\infty}) \\
\rho\end{array}$ & $\begin{array}{c}\text { Magnet- } \\
\text { ization } \\
\text { (gauss) } \\
4 \pi M_{s}\end{array}$ & $\begin{array}{c}\text { FMR line } \\
\text { width }(\mathrm{Oe}) \\
\qquad \Delta H\end{array}$ & Remarks \\
\hline$A\left(1400^{\circ} / 2 \mathrm{hr}\right)$ & $2-3$ & $5 \cdot 12$ & 1700 & $90-100$ & $\begin{array}{l}\text { Narrows to } 50 \text { Oe on } \\
\text { annealing } 1100^{\circ} / 30 \mathrm{~min} \text {. }\end{array}$ \\
\hline$B$ (repeated $A 1400^{\circ} / 8 \mathrm{hr}$ ) & 3 & $5 \cdot 13$ & 1750 & 100 & $\begin{array}{l}\text { Does not narrow on annea- } \\
\text { ling for } 10 \mathrm{hr} \text { at } 1100^{\circ} \mathrm{C} \text { and } \\
2 \mathrm{hr} \text { at } 1200^{\circ} \mathrm{C} \text {. }\end{array}$ \\
\hline $\begin{array}{l}C\left(1400^{\circ} / 8 \mathrm{hr}\right) \\
\text { Four-nine purity }\end{array}$ & 2 & $5 \cdot 14$ & 1700 & 90 & \\
\hline sol-gel sample & 5 & $5 \cdot 1$ & 1700 & 120 & \\
\hline Thomson-CSF YIG & 8 & & 1780 & 25 & \\
\hline $\mathbf{H P}_{2}$ & $1 \cdot 34$ & $5 \cdot 12$ & 1805 & 200 & \\
\hline $\mathrm{HP}_{3}$ & $1 \cdot 2$ & $5 \cdot 13$ & 1805 & 200 & \\
\hline $\mathbf{H P}_{4}$ & 0.9 & $5 \cdot 14$ & & 220 & \\
\hline $\mathrm{HP}_{5}$ & $1 \cdot 1$ & $5 \cdot 16$ & 1760 & 260 & $\begin{array}{l}\text { This sample has a wider } \\
\text { grain size distribution } \\
\text { compound to } \mathrm{HP}_{4}\end{array}$ \\
\hline
\end{tabular}




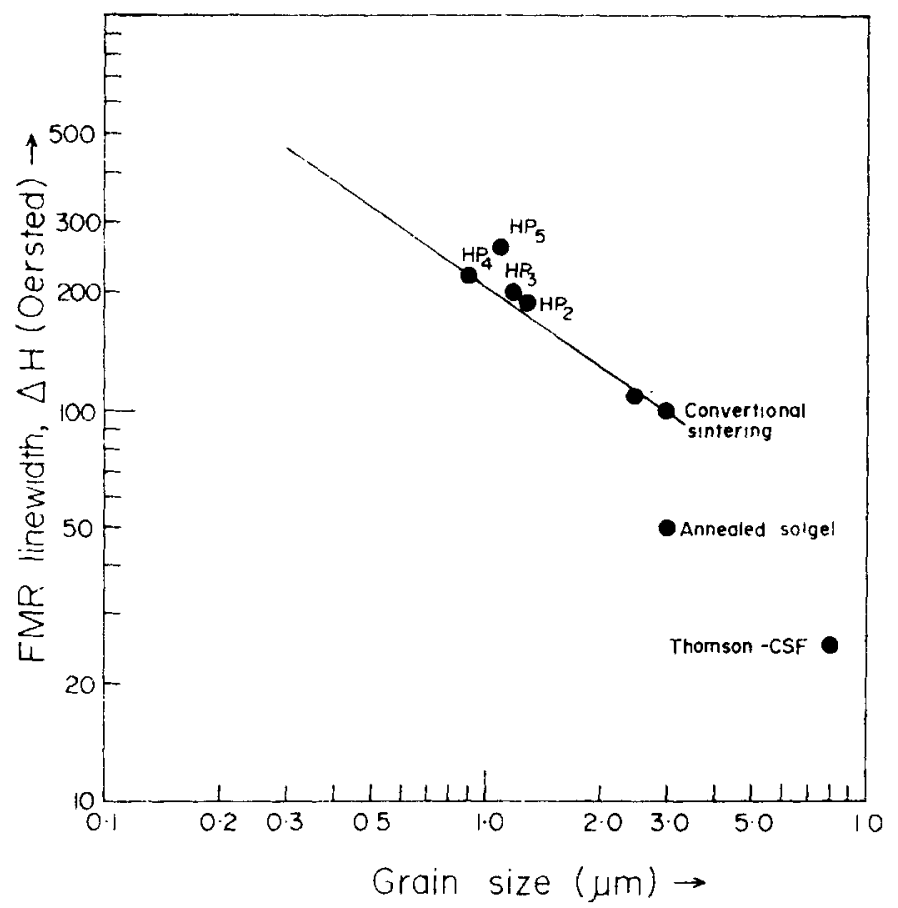

Figure 3. Uniform precession linewidth as a function of average grain diameter in polycrystalline YIG.

problem is reduced but this also reduces the pull and thereby error is increased. It was observed that with decreasing grain size susceptibility increased. This trend is not understood as one would expect a decrease in susceptibility with decreasing grain size owing to reasons: (i) as the grains become finer superparamagnetism might set in as the sample tends to reduce the wall energy and approaches single domain, (ii) increase in surface area as grain sizes decreases gives more uncoupled spins on the surface.

Mössbauer measurements in fine powders (of sizes $<0.1 \mu \mathrm{m}$ ) did not show any superparamagnetism. Two sets of six-finger hyperfine patterns corresponding to octahedral and tetrahedral sites were obtained. There was no change in hyperfine field or quadrupolar interaction on wet-milling the powder for $30 \mathrm{hr}$ in alcohol as the vehicle. Hence superparamagnetism in the sizes involved here can be ruled out. $\mathrm{HP}_{5}$ has grain size higher than $\mathrm{HP}_{4}$ as seen in scanning electron micrographs. This was supported by the susceptibility and critical field measurements, but uniform precession width $\Delta H$ for $\mathrm{HP}_{5}$ is higher than $\mathrm{HP}_{4}$. The discrepancy we think, could be due to the wider grain size distribution in $\mathrm{HP}_{5}$. Parallel pumping of microwave power at a frequency $9.6 \mathrm{GHz}$ enabled us to measure the instability threshold critical fields, $h_{\text {crit }}$ (figure 4). $h_{\text {crit }}$ is found to be inversely dependent on grain size (figure 5). In samples of grain sizes of a micron or less, the instability curve $\left(h_{\text {crit }} v s H\right)$ does not have a marked minimum as the instability sets in gradually. This leads to the difficulty of estimating the $h_{\text {crit }}$ minimum accurately.

\subsection{Discussion}

2.3a FMR linewidths. We have observed (figure 3) that there is a grain-size 


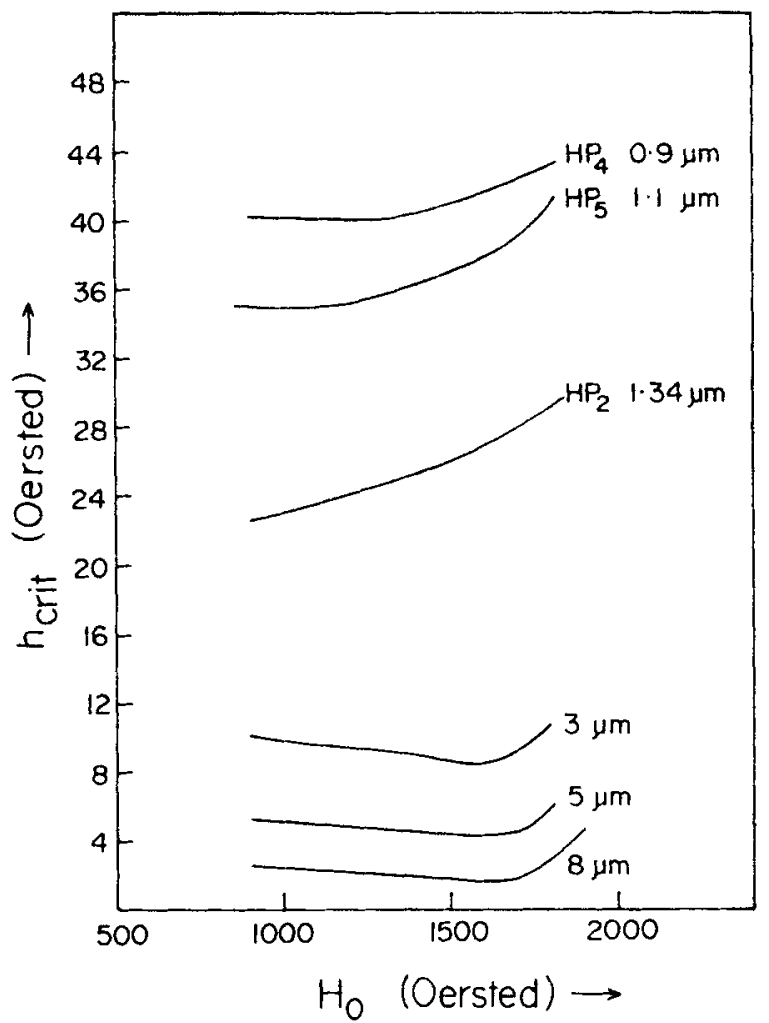

Figure 4. Spinwave instability threshold $h_{\text {crit }}$ as a function of static external magnetic field for parallel pumping at $9 \cdot 6 \mathrm{GHz}$.

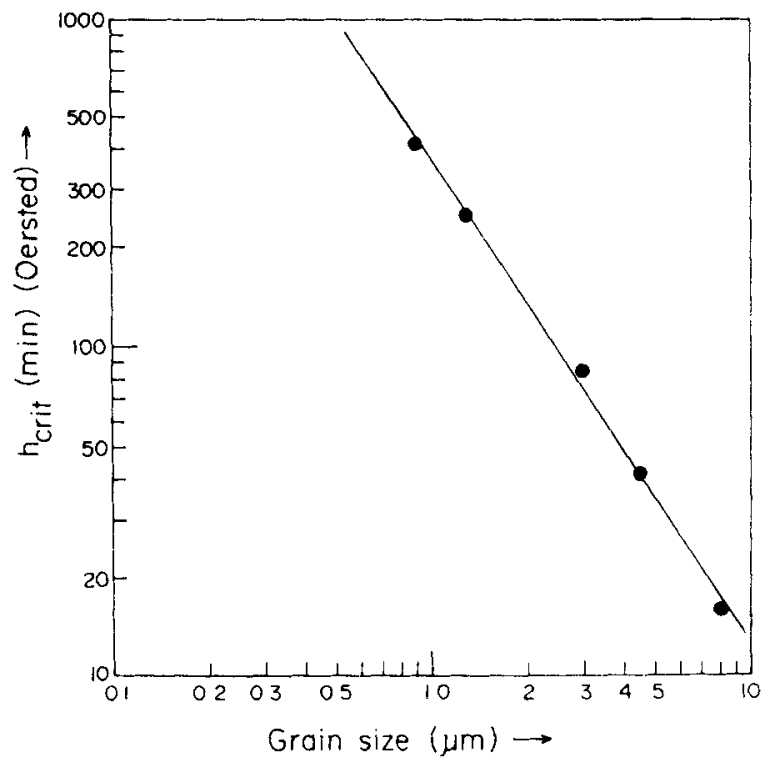

Figure 5. Spinwave instability threshold $h_{\text {crit }}$ at the butterfly minimum as a function of average grain diameter in poly-crystalline YIG. 
dependence of linewidths. The only other grain-size dependent linewidth for uniform precession was observed by Inui et al (1975) at a resonance frequency of $2 / 3 \omega_{m}$ where $\omega_{m}=\gamma 4 \pi M_{s}, M_{s}$ being saturation magnetization. This uniform precession frequency is on the top of the magnon manifold ( $\omega_{k} v s k$ curves for $\theta=0$ and $\theta=(\pi / 2)$. Inui et al (1975) had measured the widths in Sn-substituted Ga-V garnets of grain sizes varying between 8 and $30 \mu \mathrm{m}$. No explanation was given for this and other parameters like density and magnetization were also not held constant. Ferromagnetic resonance linebroadening is related to the polycrystalline nature of ferrites since a single crystal line-width in YIG is only 0.5 Oe. For a polished, spherical sample of small dimensions ( $\leqslant 1 \mathrm{~mm}$ ) contributions of linewidth are essentially due to: (i) anisotropy in the randomiy-oriented, densely-packed crystallites and (ii) porosity, including regions between crystallites, inclusions and second phase constituents.

As the resonance linewidth determines the insertion loss, bandwidth and phase shift of a device, one desires the width to be minimal. Our materials have fine grains and thereby a high threshold $h_{\text {crit }}$ but are limited by the broad widths. If one can realise the cause it would become possible to overcome it and make it best suited for devices.

The resonance linewidth at uniform precession can be written as

$$
\Delta H_{U P}=\Delta H_{i}+\Delta H_{A N}+\Delta H_{P}
$$

where $\Delta H_{i}$ is the intrinsic linewidth (of a crystal), $\Delta H_{A N}$ is the width arising due to anisotropy and $\Delta H_{P}$ is the width due to porosity. As the samples have high density, corroborated also by the high saturation magnetization, one can neglect $\Delta H_{P}$ presently. $\Delta H_{i}$ being $0.5 \mathrm{Oe}$ can also be safely neglected. Thus the width appears to be essentially determined by anisotropic field which arises owing to crystallites having their own axis of magnetization. The coercive field, which is also a measure of anisotropy has been found to depend upon grain size (Globus and Guyot 1972). Thus, a grain-size dependent contribution to linewidth of uniform precession can arise through anisotropy. The log-log plot of FMR width $v$ s grain size follows the $a^{-0.6}$ law, similar to the effective linewidth. As $\mathrm{Fe}^{3+}$ is an $S$-state ion with no spin-orbit effects and with low coercive fields, the condition $H_{A} \ll 4 \pi M_{S}$ is valid i.e. anisotropy field is less than the saturation magnetization field and one can talk within the framework of spinwave approach. For fine grains, in the low anisotropy limit, the dipolar coupling between crystallites is much greater and they tend to resonate collectively. The anisotropy line broadening should be from anisotropy field $H_{A}$ but dipole-narrowed by a factor of $H_{A} / 4 \pi M_{s}$.

Schlömann (1958) gives for spherical sample linewidths of

$$
\Delta H_{A N} \simeq\left(H_{A}^{2} / 4 \pi M_{s}\right)(8 \pi \sqrt{3} / 21) \text {. }
$$

Anisotropy field $H_{A} \simeq\left(2 k_{1} / M_{s}\right) \simeq 100$ Oe substituting, $\Delta H_{A N} \simeq 16$ Oe is the contribution due to anisotropy. Schlömann's (1958) theory also gives $26 \mathrm{Oe}$ /percent for porosity width in YIG at $10 \mathrm{GHz}$. For sample with porosity $<0.8 \%$ (our worst sample is $99 \cdot 2 \%$ dense)

$$
\Delta H_{P} \simeq 20 \mathrm{Oe}
$$

Thus $\quad \Delta H_{U P}=\Delta H_{A N}+\Delta H_{P}+\Delta H_{i} \simeq 36.5 \mathrm{Oe}$.

As $\Delta H_{i}$ also increases with increasing spinwave linewidth (as for fine grain samples) the uniform precession width is bound to be higher than the above value, but the discrepancy is large. In a fine-grain sample the spin-wave picture is modified (in our 
samples of $<1 \mu \mathrm{m}, k=10^{3} \mathrm{~cm}^{-1}$, dipolar contributions are larger than exchange) by the occurrence of magnetostatic modes, giving rise to discrete spectrum. A better relaxation and an increase in width is possible owing to this. Furthermore, an added contribution could come from the magnetoelastic or magnetostrictive effects. A large stress is introduced in the sample during sintering, compacting, grinding and polishing. Annealing for $10 \mathrm{hr}$ at $1100^{\circ} \mathrm{C}$ after making the sphere or before has not produced any change in the widths observed. Stress could also come in the pressure sintering process, inevitable in the preparation of a fine-grained materials. Röschmann (1976) arrives at the conclusion of another undefined relaxation process while explaining the widths of some ferrites. The concept of two-magnon scattering could be valid only when wavelengths are small compared to sample dimension, which condition is violated in fine-grained samples.

2.3b Critical field thresholds: The critical field $h_{\text {crit }}$ measured in a parallel pump experiment shows that a decrease in grain size increases the field $h_{\text {crit }}$. The inverse grainsize dependence of $h_{\text {crit }}$ was observed by Vrehen et al (1969) and Patton (1970), who gave the transit-time model as the most satisfying explanation. The lifetime of the excited spin wave is limited by the transit time for the mode across an individual grain i.e. $\tau_{k} \simeq a_{o} /\left|v_{g}\right|$ where $v_{g}$ is the spinwave group velocity and $a_{0}$ is the average grain diameter. Spinwave linewidth $\Delta H_{k}$ is given by

$$
\Delta H_{k} \simeq \frac{1}{\gamma \tau_{k}} \simeq \frac{\left|v_{g}\right|}{\gamma a_{o}} .
$$

A log-log plot of experimental $\Delta H_{k}$ extrapolated to $k=0\left(\Delta H_{k \rightarrow 0}\right)$ as a function of grain diameter showed

$$
\Delta H_{k \rightarrow 0} \propto a_{o}^{-1} .
$$

This model subsequently modified by Scotter (1972) and Sawado (1981) incorporating pore sizes and by Borghese (1977) with grain size distribution has reasonably explained the high $k$ regions particularly for large sizes. The theoretical fit becomes poor for fine grains and $k$ values $<10^{4} \mathrm{~cm}^{-1}$. Patton (1970) doubts the relevance of comparing parallel pump data $\Delta H_{k}$ from the transit-time model, because for grains in the micron and submicron range magnetostatic modes become important and exchange interactions are small. Our experimental 'butterfly' curves follow the results of Patton. The fine-grained samples had a gradual shifting up of instability with no marked minimum. The threshold fields were found to be high for the fine-grained samples. This is a very desirable property for high power devices but as the uniform precession linewidths are also large one has to strike a balance between the loss that can be allowed and the power handled.

\section{Amorphous and microcrystalline $\mathrm{Fe}_{2} \mathrm{O}_{3}$}

Gamma ferric oxide continues to be one of the most important materials for the magnetic recording devices. A very large number of patents cover the processes leading to $\gamma-\mathrm{Fe}_{2} \mathrm{O}_{3}$.

\subsection{Experimental}

Numerous methods have evolved for microparticle synthesis. We have devised a novel 
method based on microemulsions which have become very important in the past few years (Saffran and Turkevich 1983). In the thermodynamic equilibrium state of threecomponent microemulsion, the optically isotropic mixture consists of globular or domainlike regions of oil and water $(\sim 100 \mathrm{~A})$ with surfactant molecules at the interfaces (Shah 1981). The surfactant molecules have hydrophilic polar heads and hydrophobic hydrocarbon tails.

The systems we have used consist of an aqueous solution of ferric nitrate, 2-ethylhexanol and sorbitol-mono-oleate. The stable microemulsions were prepared for different concentrations of ferric nitrate solutions by agitating ultrasonically. Each microemulsion sample was then treated with $\mathrm{NH}_{4} \mathrm{OH}$ solution, resulting in ferric hydroxide precipitate. Now the system consisted of ferric hydroxide microparticles dispersed in an organic phase. The surfactant prevented the coagulation of the microparticles.

The microparticles were allowed to settle and then the solution was dried under infrared radiation. TGA of the dried material showed the decomposition loss between $180-250^{\circ} \mathrm{C}$. Thus, all samples were calcined at about $260^{\circ} \mathrm{C}$. The concentrations of ferric nitrate solutions and the corresponding $\mathrm{x}$-ray size are given in table 2 .

\subsection{Results and discussions}

Table 2 gives the details also of the susceptibility data at various fields. From the $x$-ray diffraction intensities it is clear that the $\gamma$ phase increases in proportion to the $\alpha$ phase when the solution concentration is reduced. At very low concentrations the materia! becomes $\mathrm{x}$-ray amorphous. The particle sizes according to the Scherrer formula are also given in table 2. TEM photographs showed spherical microparticles, with nominal agreement of physical size with $x$-ray size.

The gamma phase can be represented as a spinel structure, $\left(\square_{1 / 3} \mathrm{Fe}_{2: 3}^{3+}\right) \mathrm{Fe}_{2}^{3+} \mathrm{O}_{4}$. Haneda and Morrish (1977) have shown that the cation vacancies order for large particles but the ordering (as seen from the presence of superiattice lines in $\mathrm{x}$-ray diffraction) disappears below about $200 \AA$. In cur pure gamma samples we did not observe the superlattice peaks.

An interesting observation is through Mössbauer spectroscopy of the $150 \mathrm{~A} \gamma-\mathrm{Fe}_{2} \mathrm{O}_{3}$ microparticles and $x-r d y$ amorphou: $\mathrm{Fe}_{2} \mathrm{O}_{3}$ microparticles of $59 \mathrm{~A}$ (see figure 6). The two room-tempcrature spectra, taken much above the superparamagnetic blocking temperature, show two resonances. They correspond to the quadrupole splitting of the

Table 2. X-ray sze and DC susceptibility

\begin{tabular}{|c|c|c|c|c|c|}
\hline $\begin{array}{l}\text { Ferric nitiate: } \\
\text { solution conc. } \\
\text { Weight }\end{array}$ & $\begin{array}{c}y-\mathrm{Fe}_{2} \mathrm{O}_{3} / \mathrm{x}-\mathrm{Fe}_{2} \mathrm{O}_{3} \\
\text { from } x \text {-ray } \\
\text { diffraction }\end{array}$ & $\begin{array}{l}\text { Partule size } \\
\text { frem Scherrer } \\
\text { formula (A) }\end{array}$ & $\begin{array}{c}\chi_{m} \\
400 \mathrm{Oe}\end{array}$ & $8 \stackrel{\gamma \mathrm{kOe}}{ }$ & $\frac{\chi_{m}}{15 \mathrm{kOe} \mathrm{emu} / \mathrm{g}}$ \\
\hline 20 & 07 & 014 & 0.005 & 0.00085 & 0.00057 \\
\hline 10 & 10 & 250 & - & $\ldots$ & -- \\
\hline 5 & $1 \cdot 4$ & 190 & $\ldots$ & $\ldots$ & - \\
\hline 2.5 & Only $\gamma-\mathrm{Fe}_{2} \mathrm{O}_{3}$ & 140 & $0-006$ & 0.000748 & 0.00043 \\
\hline 1.25 & " & 80 & $0-004$ & 0.000686 & $0.0 \times 044$ \\
\hline 0.625 & " & 59 & 00015 & 0.000225 & 0,00014 \\
\hline 0.325 & Amorplious $\mathrm{Fe}_{2} \mathrm{O}_{3}$ & $\vdots$ & 0.0007 & $0000004 \dot{a}$ & 0.000042 \\
\hline
\end{tabular}




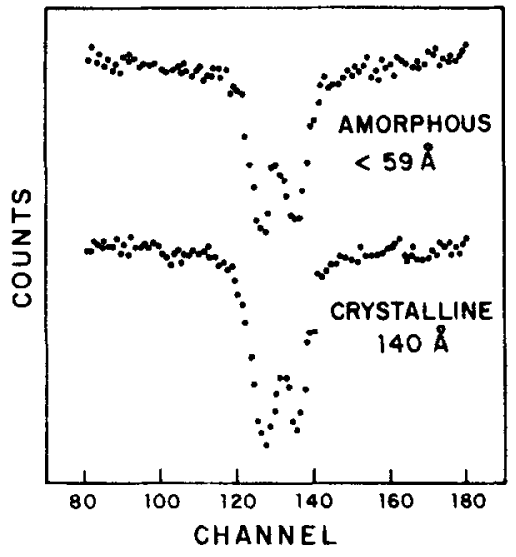

Figure 6. Mössbauer spectra above the superparamagnetic blocking temperature (A) $140 \mathrm{~A} \gamma$ - $\mathrm{Fe}_{2} \mathrm{O}_{3}$ microparticles, (B) Amorphous $\mathrm{Fe}_{2} \mathrm{O}_{3}$ microparticles $<140 \mathrm{~A}$. $v=0$ corresponds to 127.95 channel, 1 channel $=0.109 \mathrm{~mm} . \mathrm{sec}^{-1}, v$ is negative for channel below 128. $\mathrm{Co}^{57}: \mathrm{Rh}$ source, $\delta(\mathrm{Rh})=$ $+0.33 \mathrm{~mm} \cdot \mathrm{sec}^{-1}$.

$\mathrm{Fe}^{3+}\left(3 d^{5}\right)$ state in the spinel octahedral and tetrahedral sites. The asymmetry may arise due to the Goldanskaii-Karyagin effect.

Detailed Mössbauer studies are in progress.

\section{Acknowledgements}

We are grateful to the Department of Electronics for supporting the microparticle programme.

\section{References}

Bhide V G and Multani M S 1965 Phys. Ret. A139 1983

Borgese C 1977 J. Physique 38261

Glass A M, Lines M E, Nassau K and Shiever 1977a J. Appl. Phys. Lett. 31249

Glass A M, Nassau K and Shiever 1977b J. Appl. Phys. 485213

Globus A and Guyot M 1972 Phys. Status Solidi 52427

Haneda K and Morrish A H 1977 Solid State Commun. 22779

Hudson A S 1970 J. Phys. D: 3251

Inui T, Takamizawa H, Ogasawara and Fuse T 1975 AIP Conf. Proc. 24483

Känzig W, Anilkar M and Brugger H R 1954 Helv. Phys. Acta 2799

Känzig W 1955 Phys. Rev. 98549

Lines M E 1977 Phys. Rev. B15 388

Lines M E 1978 Phys. Rev. B17 1984

Multani M S, Sharma D K, Palkar V R, Gokarn S G and Gurjar A 1981 Mater. Res. Bull. 161535

Patton C E 1970 J. Appl. Phys. 41 163i

Röschmann P 1976 AIP Conf. Proc. 34253

Safran S A and Turkevich L A 1983 Phys. Rev. Lett. 501930

Sawado E 1981 Proc. International Conf. on Ferrites, University of Tokyo Press, Tokyo p. 818

Schlömann J 1958 J. Phys. Chem. Solids 6632

Scotter D G 1972 J. Phys. D: 693

Shah D O 1981 Surface phenomena in enhanced oil recovery, (New York, Plenum Press)

Srinivasan M R, Multani M S. Ayyub P and Vijayaraghavan R 1983 Ferroelectrics (to appear)

Takashige M and Nakamura 1980 J. Phys. Soc. Jpn 49B 143

Vrehen Q H F, Beljers H G and DeLau J G M 1969 IEEE Trans. MAG-5 617 